\title{
INFLUENCIA DO HIDROGEL NO CRESCIMENTO E NO TEOR DE NUTRIENTES DAS MUDAS DE Eucalyptus dunnii
}

\author{
Márcio Carlos Navroski ${ }^{1}$, Maristela Machado $\mathrm{Araújo}^{2}$, Lia Rejane Silveira Reininger ${ }^{2}$, \\ Marlove Fátima Brião Muniz ${ }^{2}$, Mariane de Oliveira Pereira ${ }^{3}$ \\ ${ }^{1}$ Universidade do Estado de Santa Catarina, Departamento de Engenharia Florestal, Lages, Santa Catarina, Brasil - \\ navroski@cav.udesc.br \\ ${ }^{2}$ Universidade Federal de Santa Maria, Santa Maria, Rio Grande do Sul, Brasil - araujo.maristela@gmail.com; liarsr@ufsm.br; \\ marlove@smail.ufsm.br \\ ${ }^{3}$ Universidade Federal do Paraná, Programa de Pós-Graduação em Engenharia Florestal, Curitiba, Paraná, Brasil - \\ maripereira.florestal@gmail.com
}

Recebido para publicação: 20/11/2013 - Aceito para publicação: 30/10/2014

Objetivou-se avaliar doses do hidro-retentor adicionado ao substrato sobre crescimento, teor nutricional e qualidade de mudas de Eucalyptus dunnii Maiden. O experimento foi realizado em delineamento inteiramente casualizado, com seis tratamentos, constituídos de concentrações crescentes do hidrogel ( 0 ; 1,$5 ; 3,0 ; 4,5$ e 6,0 g. $\mathrm{L}^{-1}$ ). Foram utilizadas seis repetições, cada uma composta por 24 plantas. Aos 90 dias após a semeadura, foi realizada a avaliação de parâmetros morfológicos das mudas e análise nutricional da parte aérea. A dose em torno de 4,5 g.L. $\mathrm{L}^{-1}$ ocasiona a melhor resposta quanto às variáveis avaliadas, proporcionando maior altura, diâmetro de coleto, massa seca da parte aérea e radicular e índice de qualidade de Dickson. O uso de doses abaixo de $3 \mathrm{~g} . \mathrm{L}^{-1}$ ou acima de 4,5 g. $\mathrm{L}^{-1}$ diminuíram a qualidade das mudas. Todos os macronutrientes apresentaram maior teor na parte aérea (caule + folhas) na presença do hidrogel. $\mathrm{O}$ teor dos macronutrientes na parte aérea das mudas aumenta com a adição do hidrogel, porém diminui o teor dos micronutrientes. Em geral, o uso do polímero hidro-retentor aumentou a qualidade das mudas de E. dunnii.

Palavras-chave: Produção de mudas; polímero hidroretentor; retenção de água e nutrientes; análise nutricional.

\begin{abstract}
Doses of hydrogel influencing growth and nutritional content in seedlings Eucalyptus dunnii. The objective was to evaluate different dosages of hidroretentor added to the substrate on the growth, nutrient content and quality of Eucalyptus dunnii Maiden. The experiment was conducted in a completely randomized design with six treatments, and increasing concentrations of the hydrogel $(0$, 1.5, 3.0, 4.5 and 6.0 g. $\mathrm{L}^{-1}$ ). Were six replicates, each consisting of 24 plants. At 90 days after sowing was evaluated morphological parameters of seedlings and nutritional analysis of the seedlings. The dose around $4.5 \mathrm{~g} . \mathrm{L}^{-1}$ brings the best answer for the variables evaluated, providing greater height, diameter collect, shoot dry mass, root parts and Dickson quality index. The use of doses below $3 \mathrm{~g}$.L

${ }^{1}$ or above 4.5 g.L ${ }^{-1}$ decreased the quality of seedlings. All macronutrients showed higher content in shoots (leaves + stem) in the presence of the hydrogel. The macronutrient content of the shoots of seedlings increases with the addition of the hydrogel, but decreases the content of micronutrients. In general, the use of polymer hidroretentor increased the quality of the seedlings of E. dunnii.

Keywords: Seedling production; polymer hidroretentor; retention of water and nutrients; nutritional analysis.
\end{abstract}

\section{INTRODUÇÃO}

Uma das principais etapas da silvicultura de Eucalyptus é a produção de mudas de qualidade, pois delas depende o desempenho final das plantas no campo de produção. Para se obter mudas de qualidade, é necessária a utilização de técnicas adequadas de formação e, dentre os fatores importantes, destacam-se as propriedades do substrato, o nível de nutrição e a disponibilidade de água às mudas.

Uma técnica ainda pouco estudada é a adição de polímeros hidro-retentores como condicionadores hídricos de substrato, com vistas a aumentar a capacidade de retenção de água em substratos para mudas, propiciando melhor qualidade (MARQUES; BASTOS, 2010). 
Polímeros hidro-retentores, também chamados de hidrogel ou polímeros retentores de água, são produtos naturais (derivados do amido) ou sintéticos (derivados do petróleo), valorizados por sua capacidade de absorver e armazenar água. Quebradiços quando secos, eles se tornam macios e elásticos depois de expandidos em água. Muito embora, exteriormente, um polímero hidro-retentor possa parecer semelhante a outro, a composição química e estrutura física de cada um podem ser diferentes, o que afeta a maneira como eles absorverão, reterão e liberarão água (MORAES et al., 2001). Capazes de armazenar muitas vezes o próprio peso em água, os polímeros hidro-retentores produzem numerosos ciclos de secagem-irrigação, por longo tempo de duração (MELO et al., 2005).

A adição dos polímeros hidro-retentores ao solo contribui para germinação de sementes, desenvolvimento do sistema radicular, crescimento e desenvolvimento das plantas, redução das perdas de água de irrigação por percolação e melhoria na aeração e drenagem do solo, além de redução das perdas de nutrientes por lixiviação (CÂMARA et al., 2011; AZEVEDO et al., 2002).

Como o polímero reduz a perda de umidade e nutrientes incorporados ao meio de cultivo, podese melhorar ainda mais o meio em que as plantas irão se desenvolver. Como as plantas absorvem água e nutrientes por meio de suas raízes, é interessante saber se esses polímeros são capazes de aumentar a retenção dos fertilizantes. Isso poderia otimizar as possibilidades de aplicação de tais produtos, devido à sua eficiência máxima no uso de fertilizante, minimizando a poluição do solo e de água subterrânea (COTTHEM, 1998). Uma boa forma para monitorar a fertilização é por meio da análise nutricional foliar, a qual mostra os teores de nutrientes que a planta assimilou. Por meio de sua análise e controle do crescimento das plantas, é possível identificar quando os nutrientes limitam o crescimento e se estão na disponibilidade ideal ou causando toxicidade no crescimento (JACOBS; LANDIS, 2009).

No crescimento das plantas, diversos são os fatores que afetam a disponibilidade de nutrientes, como o meio de crescimento (substrato), valores de $\mathrm{pH}$, irrigação, salinidade da solução, fonte de nutrientes, umidade, temperatura e associações simbióticas, entre outros, sendo várias dessas características modificadas pela adição do hidrogel ao substrato. Assim, se as condições de cultivo são adequadas, sem que ocorram estresses às plantas, a espécie irá responder conforme sua necessidade, de acordo com seu estágio de crescimento.

Um dos fatores mais limitantes ao uso desses polímeros é o seu custo, ainda elevado. Porém podem ser obtidos resultados positivos com doses baixas. Essas pequenas doses podem trazer a melhoria das condições de retenção de água e nutrientes no substrato, propiciando mais uma alternativa na produção de mudas de Eucalyptus com menores custos (HAFLE et al., 2008). Estudo com Anadenanthera peregrina (L.) Speg demonstrou que dosagens baixas do polímero hidro-retentor (menor de 4 g. $\mathrm{L}^{-1}$ ) podem melhorar a qualidade das mudas, não sendo recomendadas doses muito altas para a espécie (SOUSA et al., 2013).

Apesar das propriedades promissoras que os polímeros hidro-retentores apresentam, são necessários estudos para a determinação de seus reais efeitos nas propriedades do solo e no comportamento das plantas, buscando-se identificar dosagens adequadas de cada produto. Justifica-se, assim, a realização de experimentos para a confirmação das características favoráveis dos polímeros e obtenção de resultados sobre sua real eficiência no desenvolvimento das plantas (DUSI, 2005).

Estudos na literatura recente têm mostrado efeito benéfico da utilização dos polímeros hidroretentores incorporados ao substrato para a produção de mudas de algumas espécies. Vários estudos foram realizados com café (Coffea arabica L.), destacando-se os trabalhos de Lima et al. (2003), Melo et al. (2005) e Marques et al. (2013). Moreira et al. (2010) constataram que a incorporação do polímero hidro-retentor ao substrato favoreceu o desenvolvimento de mudas de amoreira (Morus sp.). Bernardi et al. (2012) verificaram maior crescimento da parte aérea em mudas de eucalipto (Corymbia citriodora $\mathrm{F}$. Muell) que foram produzidas utilizando esse polímero.

Dessa forma, objetivou-se com este trabalho avaliar diferentes doses do hidro-retentor adicionado ao substrato de plantio no crescimento, teor de nutrientes e qualidade de mudas de Eucalyptus dunnii Maiden.

\section{MATERIAL E MÉTODOS}

\section{Produção e crescimento das mudas}

O estudo foi conduzido no Viveiro Florestal do Departamento de Ciências Florestais (2943' S; $53^{\circ} 43^{\prime}$ W) da Universidade Federal de Santa Maria (UFSM), entre agosto e novembro de 2012. Conforme os dados do Instituto Nacional de Meteorologia (INMET) (2013), a temperatura média durante o período de realização do experimento foi de $20,11^{\circ} \mathrm{C}$ e a umidade relativa do ar, de $76,0 \%$. 
$\mathrm{O}$ experimento foi realizado em delineamento inteiramente casualizado, com seis tratamentos, constituídos de concentrações crescentes do polímero hidro-retentor $(0,1,5,3,0,4,5$ e $6,0 \mathrm{~g}$ de gel hidroretentor a cada litro de substrato). Foram utilizadas cinco repetições, cada uma composta por 24 plantas, sendo posteriormente consideradas para avaliação as oito plantas centrais de cada parcela.

As sementes de E. dunnii utilizadas são originárias de Área de Produção de Sementes da empresa da qual foi feita a aquisição do material. Conforme os dados fornecidos pela empresa, o lote possuía pureza de $90 \%$ e porcentagem de geminação média de $80 \%$. Após a aquisição das sementes até a semeadura (aproximadamente $1 \mathrm{ano}$ ), as sementes foram acondicionadas em embalagem de plástico semipermeável (90 micras de espessura) e armazenadas em câmara fria $\left(\mathrm{T}=8{ }^{\circ} \mathrm{C}\right.$; UR $\left.=85 \%\right)$.

Para a instalação do experimento, foram utilizados tubetes com a capacidade de $110 \mathrm{~cm}^{3}$. Ao substrato, foram adicionados polímero hidro-retentor e adubação. A adubação de base utilizada foi composta de adubo NPK, na quantidade de $0,6 \mathrm{~g}$ de nitrogênio - ureia $(45 \% \mathrm{~N}), 4,0 \mathrm{~g}$ de fósforo (45\% $\left.\mathrm{P}_{2} \mathrm{O}_{5}\right)$ e $0,4 \mathrm{~g}$ de potássio $-\mathrm{K}_{2} \mathrm{SO}_{4}\left(45 \% \mathrm{~K}_{2} \mathrm{O}\right)$ a cada litro de substrato utilizado. A semeadura foi efetuada colocando-se duas sementes em cada recipiente. Para a cobertura das sementes, foi utilizada uma pequena camada de vermiculita fina.

O substrato utilizado foi de origem comercial $\left(\right.$ Carolina Soil ${ }^{\circledR}$ ), composto à base de turfa de Sphagnum, vermiculita expandida, calcário dolomítico, gesso agrícola e fertilizante NPK. As características descritas para o produto, conforme o fabricante, são: $\mathrm{pH}=5,0( \pm 0,5)$; condutividade elétrica $=0,7\left( \pm 0,3 \mathrm{mS} \cdot \mathrm{cm}^{-1}\right)$; densidade $=101 \mathrm{~kg} \cdot \mathrm{m}^{3} ;$ capacidade de retenção de água $-\mathrm{CRA}=55 \%$; e umidade máxima $=60 \%$. A caracterização física e química dos substratos com as respectivas misturas de hidro-retentor, conforme os tratamentos, foi realizada no Laboratório de Substratos do Departamento de Horticultura e Silvicultura da Universidade Federal do Rio Grande do Sul, conforme a Instrução Normativa $\mathrm{n}^{\mathrm{o}} 17$ do Ministério da Agricultura, Pecuária e Abastecimento (MAPA, 2007) e Fermino (2003). Os resultados da análise química e física dos substratos estão na tabela 1.

Tabela 1. Análise do substrato comercial (Carolina Soil ${ }^{\circledR}$ ) em cada uma das doses de hidrogel testadas na produção de mudas de Eucalyptus dunnii.

Table 1. Analysis of commercial substrate (Carolina Soil $\left.{ }^{\circledR}\right)$ in each of the doses tested hydrogel in seedlings of Eucalyptus dunnii.

\begin{tabular}{|c|c|c|c|c|c|}
\hline \multirow{2}{*}{$\begin{array}{l}\text { Atributos } \\
\text { analisados }\end{array}$} & \multicolumn{5}{|c|}{ Hidrogel $\left(\mathrm{g} . \mathrm{L}^{-1}\right)$} \\
\hline & 0 g.L L $^{-1}$ & 1,5 g.L ${ }^{-1}$ & 3 g.L ${ }^{-1}$ & 4,5 g.L ${ }^{-1}$ & 6 g.. $\mathrm{L}^{-1}$ \\
\hline PT (\%) & 80,81 & 84,16 & 90,50 & 95,49 & 98,00 \\
\hline EA $(\%)$ & 25,33 & 24,67 & 21,67 & 20,58 & 19,35 \\
\hline $\mathrm{AD}(\%)$ & 22,61 & 25,01 & 25,76 & 30,78 & 33,3 \\
\hline AFD (\%) & 19,07 & 22,39 & 22,91 & 25,79 & 28,23 \\
\hline $\mathrm{AT}(\%)$ & 2,62 & 2,84 & 3,54 & 4,99 & 5,08 \\
\hline $\operatorname{AR}(\%)$ & 32,86 & 37,47 & 39,91 & 44,13 & 45,33 \\
\hline CRA10 (\%) & 55,48 & 62,49 & 65,67 & 74,91 & 78,64 \\
\hline CRA50 (\%) & 36,40 & 40,09 & 42,76 & 49,12 & 50,41 \\
\hline CRA100 (\%) & 32,86 & 37,47 & 39,91 & 44,13 & 45,33 \\
\hline $\mathrm{pH}$ & 4,87 & 5,59 & 5,66 & 6,01 & 6,31 \\
\hline $\mathrm{CE}\left(\mathrm{mS} \cdot \mathrm{cm}^{-1}\right)$ & 0,46 & 0,47 & 0,48 & 0,49 & 0,59 \\
\hline
\end{tabular}

PT: porosidade total; EA: espaço de aeração; AD: água disponível; AFD: água facilmente disponível; AT: água tamponante; AR: água remanescente; CRA10, 50 e 100: capacidade de retenção de água sob sucção de 10, 50 e 100 cm de coluna de água; CE: condutividade elétrica.

O polímero comercial utilizado (Hydroplan - $\mathrm{EB}^{\circledR}$ ) correspondeu a um produto misto de copolímero reticulado de acrilamida $\left(\mathrm{C}_{3} \mathrm{H}_{5} \mathrm{NO}\right)$ e acrilato de potássio $\left(\mathrm{K}_{2} \mathrm{~S}_{2} \mathrm{O}_{8}\right)$ usado para absorver e reter grandes quantidades de água e nutrientes, com as seguintes características: pó, microgrânulos ou grânulos, branco insolúvel em água, com partículas de tamanho que variam de 0,3 a 1,0 mm, aniônico, com $10 \%$ de umidade, densidade de $0,8 \mathrm{~g} \cdot \mathrm{cm}^{-3}$ e índice de $\mathrm{pH}$ utilizável de 5 a 9 , que pode disponibilizar até $95 \%$ da solução armazenada para a planta (5\% retidos a alta tensão), capaz de absorver até 300 vezes sua massa em água e 100 vezes seu volume, sendo compatível com a maioria dos insumos utilizados, porém com capacidade de retenção afetada e vida útil que varia de 1 a 5 anos (SAAD et al., 2009).

Para proporcionar uma mistura homogênea e garantir uma boa distribuição do polímero e do fertilizante ao substrato foi utilizada a porção de 5 litros de substrato a cada mistura. Após a mistura do polímero e do adubo, procedeu-se ao preenchimento dos tubetes com substrato, conforme cada 
tratamento. Eles foram dispostos nas bandejas e, em seguida, submetidos a mesa vibratória por aproximadamente 10 segundos. Buscou-se um preenchimento dos tubetes em aproximadamente $80 \%$ do volume máximo possível, para evitar derramamento do substrato após a hidratação com o hidrogel, devido à expansão das partículas do hidro-retentor durante a sua hidratação.

Após a semeadura, as bandejas foram levadas à casa de vegetação, onde permaneceram até a avaliação do experimento (90 dias). Com 40 dias, procedeu-se ao raleio das mudas, permanecendo no recipiente a mais vigorosa e centralizada. Aos 60 dias, procedeu-se à diminuição da densidade das mudas na bandeja em 50\%, passando da densidade inicial de 400 plantas $/ \mathrm{m}^{2}$ para 200 plantas $/ \mathrm{m}^{2}$.

A irrigação foi realizada por um sistema de microaspersão, com uma lâmina de irrigação de $4 \mathrm{~mm} /$ dia, acionada por um timer às 8:00 $\mathrm{h}$, às 11:00 h, às 14:00 h e a última às 17:00 h. Optou-se em realizar todo o experimento em casa de vegetação com irrigação constante, para melhor visualizar os efeitos do gel hidro-retentor e as diferentes doses de adubação.

A avaliação foi efetuada aos 90 dias após a semeadura, por meio das seguintes variáveis: altura da parte aérea (desde o colo até o ápice do caule) (H), diâmetro do colo (DC), relação altura/diâmetro (H/DC), massa seca da parte aérea (MSPA), massa seca radicular (MSR) e massa seca total (MST). Também foi calculado o Indice de Qualidade de Dickson (IQD), segundo Dickson et al. (1960).

Para obtenção da massa seca, as mudas foram cortadas e separadas em parte aérea e radicular. A parte radicular contendo o substrato foi lavada em água corrente e, com auxílio de peneiras, foi efetuada a separação das raízes. Tanto as raízes quanto a parte aérea foram secas em estufa com temperatura de $70^{\circ} \mathrm{C}$ até atingir massa constante, sendo após quantificada em balança de precisão.

\section{Análise nutricional da parte aérea das mudas}

As análises químicas da parte aérea das mudas foram realizadas no Laboratório de Ecologia Florestal do Departamento de Ciências Florestais da Universidade Federal de Santa Maria. Em todas as amostras de tecido vegetal (três repetições por tratamento), após a secagem $\left(70{ }^{\circ} \mathrm{C}\right)$ e moagem, foi realizada a determinação dos teores de macro $(\mathrm{N}, \mathrm{P}, \mathrm{K}, \mathrm{Ca}, \mathrm{Mg}$ e $\mathrm{S})$ e micronutrientes $(\mathrm{B}, \mathrm{Cu}, \mathrm{Fe}, \mathrm{Mn}$ e $\mathrm{Zn}$ ). O nitrogênio foi determinado pelo método Kjeldahl (digestão sulfúrica $=\mathrm{H}_{2} \mathrm{SO}_{4}+\mathrm{H}_{2} \mathrm{O}_{2}$ ); fósforo e boro por espectrofotometria de absorção atômica (P por digestão nítrica-perclórica e $\mathrm{B}$ por digestão seca); potássio por fotometria de chama; enxofre por turbidimetria; e cálcio, magnésio, cobre, ferro, manganês e zinco por espectrometria de absorção atômica (todos por digestão nitricoperclórica), seguindo a metodologia descrita por Tedesco et al. (1995) e Miyazawa (1999).

\section{Procedimentos estatísticos}

Após ser avaliada a normalidade pelo teste de Kolmogorov-Smirnov e a homogeneidade de variâncias por meio do teste de Bartlett, os dados foram submetidos à análise de variância ao nível de 5\% de probabilidade de erro. Quando o valor de "F" foi significativo, os tratamentos foram submetidos a análise de regressão polinomial. No caso de efeito significativo de equações quadráticas, determinou-se a dose de máxima eficiência técnica (MET). O pacote estatístico SISVAR (FERREIRA, 2011) foi utilizado para a análise dos dados. Também foi realizada a análise de correlação de Pearson entre as variáveis morfológicas.

\section{RESULTADOS E DISCUSSÃO}

\section{Produção e crescimento das mudas}

A análise de variância indicou diferença significativa $(p<0,05)$ entre os tratamentos para todas as variáveis avaliadas, com exceção da relação H/DC $(p>0,05)$. A partir da análise de correlação de Pearson apresentada na tabela 2, pode-se observar que a maioria das variáveis estudadas apresentou correlação significativa. A variável altura apresentou um índice de correlação médio a alto quando relacionada com o diâmetro do colo, mostrando que, em geral, as mudas de maior altura apresentaram maior diâmetro. Para essa relação resultar significativa, é importante diminuir a densidade das mudas para que ocorra o incremento em diâmetro. A MST e o IQD apresentaram em média as maiores correlações entre as variáveis.

Em relação ao crescimento, a altura média das mudas seguiu uma função quadrática, aumentando até atingir a máxima eficiência técnica (MET). A dose de $4,5 \mathrm{~g} . \mathrm{L}^{-1}$ proporcionou o maior valor, aproximando-se de $25 \mathrm{~cm}$ e apresentando uma MET em 6,3 g.L $\mathrm{L}^{-1}$. Em comparação com a ausência 
do hidrogel, é possível visualizar um ganho significativo na altura das mudas, observando-se um aumento de aproximadamente $10 \mathrm{~cm}$ quando se fez uso de $4,5 \mathrm{~g} . \mathrm{L}^{-1}$ do polímero (Figura $1 \mathrm{~A}$ ).

Tabela 2. Coeficiente de correlação de Pearson entre as variáveis altura (H), diâmetro do colo (DC), relação H/DC, massa seca da parte aérea (MSPA), massa seca radicular (MSR), massa seca total (MST) e Índice de Qualidade de Dickson (IQD) em mudas de Eucalyptus dunnii.

Table 2. Pearson correlation coefficient amongst the variables height $(\mathrm{H})$, stem diameter (DC), H/DC, dry weight of shoot (MSPA), root biomass (MSR), total dry matter (MST) and index Dickson quality (IQD) in seedlings of Eucalyptus dunnii.

\begin{tabular}{lccccccc}
\hline Variável & $\mathbf{H}$ & $\mathbf{D C}$ & $\mathbf{H} / \mathbf{D C}$ & MSPA & MSR & MST & IQD \\
\hline $\mathrm{H}$ & 1 & $0,63^{*}$ & $0,59^{*}$ & $0,98^{*}$ & $0,57^{*}$ & $0,96^{*}$ & $0,55^{*}$ \\
DC & & 1 & $-0,21^{\text {ns }}$ & $0,62^{*}$ & $0,23^{\text {ns }}$ & $0,58^{*}$ & $0,73^{*}$ \\
H/DC & & & 1 & $0,56^{*}$ & $0,50^{*}$ & $0,59^{*}$ & $-0,07^{\text {ns }}$ \\
MSPA & & & & 1 & $0,57^{*}$ & $0,98^{*}$ & $0,61^{*}$ \\
MSR & & & & & 1 & $0,72^{*}$ & $0,71^{*}$ \\
MST & & & & & & 1 & $0,68^{*}$ \\
IQD & & & & & & & 1 \\
\hline
\end{tabular}

${ }^{*}$ : Coeficientes de correlação de Pearson significativos a $5 \%$ de probabilidade de erro; ${ }^{\text {ns}}$ : coeficientes de correlação de Pearson não significativos a $5 \%$ de probabilidade de erro.
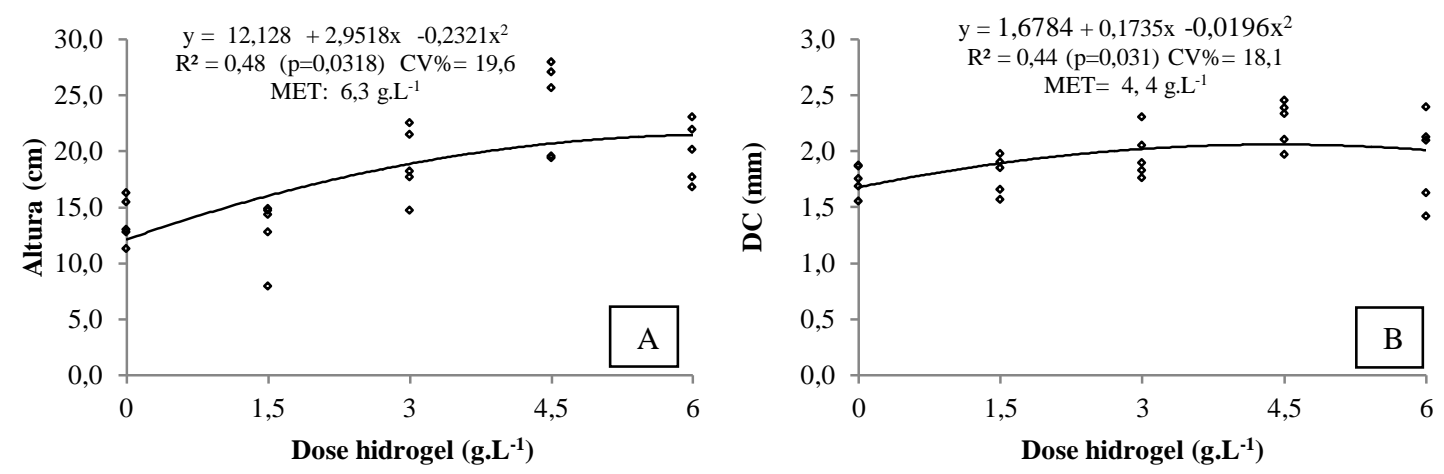

Figura 1. A - altura (cm) e B - diâmetro de colo (mm) de mudas de Eucalyptus dunnii em função do uso de diferentes doses de polímero hidro-retentor aos 90 dias após a semeadura.

Figure 1. A - height $(\mathrm{cm})$ and B - stem diameter $(\mathrm{mm})$ of seedlings of Eucalyptus dunnii according to the use of different dosage of hidroretentor polymer at 90 days after sowing.

A dose do hidrogel de $1,5 \mathrm{~g} . \mathrm{L}^{-1}$ não apresentou modificação na altura das mudas em relação à testemunha. Já o uso de $3,0 \mathrm{~g} . \mathrm{L}^{-1}$ apresentou comportamento praticamente equivalente ao da maior dose utilizada. $\mathrm{O}$ uso da dose $3,0 \mathrm{~g} . \mathrm{L}^{-1}$ pode representar diminuição dos gastos, devido à redução no uso do polímero, atingindo resultados similares aos encontrados na maior dose. As indicações dos produtos comerciais de hidrogel recomendam o uso de $6,0 \mathrm{~g} . \mathrm{L}^{-1}$, porém, observando-se a altura das mudas, uma diminuição dessa quantidade é possível e recomendada. Entretanto, esse comportamento pode ser alterado com o uso de diferentes substratos, ambientes e níveis de irrigação.

Nem sempre maior altura significa melhor qualidade, pois mudas muito altas podem comprometer o reflorestamento, por tombarem com mais facilidade, apresentarem menor taxa de crescimento e menor índice de sobrevivência no campo (ARAÚJO, 2009). O diâmetro do coleto também deve ser maior nas mudas que têm maior altura, para não haver o tombamento (fato verificado na análise de correlação de Pearson). Neste estudo, as mudas com maior altura do tratamento com $4,5 \mathrm{~g} . \mathrm{L}^{-1}$ possuem boa qualidade, pois a variável diâmetro de coleto também apresentou resultados superiores para esse tratamento (Figura 1B).

Em relação ao diâmetro de coleto, a dose usual de 6 g. $\mathrm{L}^{-1}$ alcançou resultado inferior nas duas variáveis em comparação com a dose de $4,5 \mathrm{~g} \cdot \mathrm{L}^{-1}$. A diminuição da altura e diâmetro de coleto com o uso da maior dose do hidro-retentor pode ser decorrente do excesso de água e nutrientes armazenados no

FLORESTA, Curitiba, PR, v. 45, n. 2, p. 315 - 328, abr. / jun. 2015.

Navroski. M. C. et al.

ISSN eletrônico 1982-4688 / ISSN impresso 0015-3826

DOI: $10.5380 /$ rf.v45i2.34411 
substrato, que pode ocasionar a diminuição do crescimento. Como foi visto na análise do substrato (Tabela 1), a adição de altas doses do hidrogel aumenta a retenção de água, principalmente em relação à água remanescente, que, quando em excesso, pode reduzir a aeração das raízes.

Além disso, o substrato comercial utilizado possui componentes como a turfa de Sphagnum e a vermiculita expandida, que são materiais com alta capacidade de retenção de água (KÄMPF, 2005; WENDLING et al., 2002), o que pode provocar o excesso de água e nutrientes no meio de cultivo com maiores dosagens do hidrogel. Dessa forma, a utilização de componentes com menor capacidade de retenção de água na composição dos substratos, como a casca de arroz carbonizada, por exemplo, pode modificar o comportamento das variáveis avaliadas, conforme a variação da dose do hidrogel.

A não utilização do hidrogel no substrato ocasionou um menor diâmetro de coleto nas mudas de E. dunnii, sendo observada uma elevação do DC com o aumento da dose do hidrogel até 4,4 g.L $\mathrm{L}^{-1}$, ponto no qual há uma tendência de diminuição do DC, sendo também o ponto que reflete a máxima eficiência do hidro-retentor. Corroborando esses resultados, Sousa et al. (2013), testando a aplicação do polímero hidro-retentor adicionado ao substrato na produção de mudas de Anadenanthera peregrina, encontrou maior diâmetro das mudas utilizando a dosagem de 4,0 g.L $\mathrm{L}^{-1}$. Por outro lado, Bernardi et al. (2012) verificaram maior incremento em altura $(22,99 \%)$ e diâmetro $(23,12 \%)$ para mudas de Corymbia citriodora produzidas com 6 g. $\mathrm{L}^{-1}$, quando comparadas com mudas produzidas sem a adição do produto, na mesma adubação.

O tempo de manutenção das mudas de Eucalyptus na fase de viveiro pode variar de 90 a 120 dias, dependendo das condições de cultivo, espécie e fatores ambientais, como temperatura e umidade (GOMES et al., 2003). Neste estudo, utilizando a dose de 4,5 g.L $\mathrm{L}^{-1}$ de hidrogel, foi possível obter mudas com altura e diâmetro de coleto adequados para o plantio em apenas 90 dias, de acordo com o tamanho desejado por empresas e recomendado em alguns trabalhos científicos. Nesse sentido, trabalhando com produção de mudas de diversas espécies florestais, Sturion e Antunes (2000) recomendam a retirada de mudas de eucalipto da casa de vegetação quando estas atingirem em torno de 15 a $25 \mathrm{~cm}$ de altura e diâmetro do coleto de 2,5 mm. De acordo com Gomes et al. (1996), as características nas quais as empresas florestais se fundamentam para a classificação das mudas de eucaliptos são baseadas nos parâmetros de altura média entre 15 e $30 \mathrm{~cm}$ e diâmetro do coleto de $2 \mathrm{~mm}$.

Em relação à massa seca da parte aérea (MSPA), há uma grande variação entre os tratamentos, com tendência de aumento da massa de forma progressiva até a dose de MET $\left(4,9 \mathrm{~g} . \mathrm{L}^{-1}\right)$ e uma tendência de queda relativamente acentuada com o uso da dose $6,0 \mathrm{~g} . \mathrm{L}^{-1}$. Com o uso das doses 0 e $1,5 \mathrm{~g} . \mathrm{L}^{-1}$, as plantas cultivadas apresentaram menores médias de massa seca da parte aérea das mudas, em relação às demais, tendo sido afetado seu desenvolvimento, fato que foi comprovado pela diminuição da altura e diâmetro de coleto quando se fez o uso desses tratamentos (Figura 2A).

$\mathrm{O}$ uso de doses mais baixas do hidrogel, principalmente $1,5 \mathrm{~g} . \mathrm{L}^{-1}$, praticamente não apresenta ganho de MSPA. Com o aumento da dose, há um ganho expressivo de massa seca em comparação com a ausência de hidrogel ou o uso de doses muito baixas. A maior eficiência foi obtida com a dose 4,9 g.. $\mathrm{L}^{-1}$, que alcançou a máxima massa seca da parte aérea, sendo que o uso superior a essa dose ocasiona diminuição de massa seca e também aumento do custo com o polímero.

Para a MSR, o comportamento foi relativamente diferente em relação ao das demais variáveis. Nesse caso, embora tenha havido uma tendência de estabilização, o maior valor de massa seca radicular foi obtido com o uso da dose 5,6 g. $\mathrm{L}^{-1}$ do hidrogel. Observou-se uma tendência de aumento da massa seca com o aumento da dose do hidrogel (Figura 2B). Mesmo a menor dose do hidrogel foi responsável por uma maior formação de raízes, diferentemente das outras variáveis, em que, nessa dose, foi observado baixo ganho ou mesmo nenhum em comparação com a ausência do hidro-retentor. Comportamento diferenciado do uso do polímero na massa seca radicular foi observado por Sousa et al. (2013) em Anadenanthera peregrina. Conforme os autores, dosagens acima de $4 \mathrm{~g} . \mathrm{L}^{-1}$ influenciaram negativamente a qualidade e o desenvolvimento das mudas, principalmente no que se refere à formação do sistema radicular.

A massa seca de raízes apresenta boa resposta ao uso do hidrogel. Essa variável apresenta expressiva importância no desenvolvimento das plantas, pois, quando estão bem enraizadas, elas apresentam maior capacidade de crescimento e maior potencial de sobrevivência em campo (ELOY et al., 2013). A maior dose do hidrogel proporcionou maior massa de raízes, provavelmente devido à maior disponibilidade de água e de nutrientes. Entretanto, isso não refletiu no aumento de outras variáveis, como altura, diâmetro do coleto e massa seca da parte aérea.

A MST apresentou comportamento semelhante ao das outras variáveis (Figura 2C), com exceção da massa seca radicular. Novamente, a dose $4,5 \mathrm{~g} . \mathrm{L}^{-1}$ apresentou o maior valor, com a máxima eficiência 
técnica de 5,1 g.L $\mathrm{L}^{-1}$. Como a massa seca da parte aérea representa maior porcentagem da massa seca total, obteve-se um comportamento muito similar (confirmado pela correlação de Pearson). A maior diferença foi observada na dose de $1,5 \mathrm{~g} . \mathrm{L}^{-1}$, na qual a massa seca da parte aérea não apresentou ampla diferença (17,9\% a mais de MST) da ausência do hidrogel. Já a massa seca radicular foi maior com o uso de $1,5 \mathrm{~g} . \mathrm{L}^{-1}$ em comparação com a dose 0 g.. $\mathrm{L}^{-1}$. A produção de matéria seca total é uma boa variável para avaliar o crescimento das plantas, por ser reflexo direto da fotossíntese líquida total (ENGEL; POGGIANI, 1990).
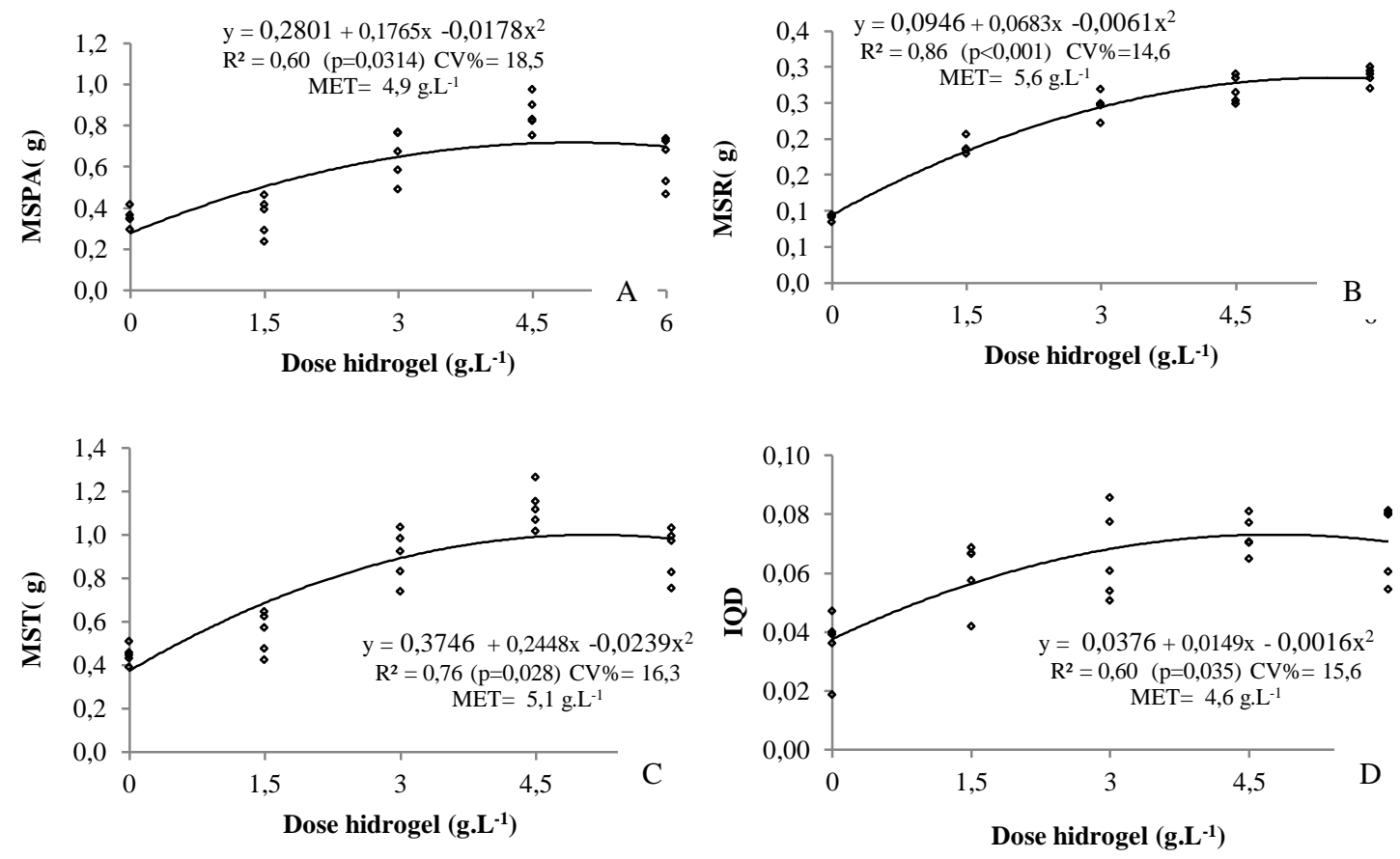

Figura 2. Massa seca da parte aérea (A), massa seca radicular (B), massa seca total (C) e Índice de Qualidade de Dickson (D) de mudas de Eucalyptus dunnii em função do uso de diferentes doses de polímero hidro-retentor aos 90 dias após semeadura.

Figure 2. Dry weight of shoot (A), root biomass (B), total dry mass (C) and Dickson Quality Index (D) of seedlings of Eucalyptus dunnii according to the use of different dosages of hidroretentor polymer at 90 days after sowing.

O Índice de Qualidade de Dickson (IQD) foi maior nas maiores doses de hidrogel utilizadas, apresentando um ponto máximo na dose de 4,6, diminuindo a partir desse nível (Figura 2D). O índice é consideravelmente maior na utilização do hidrogel em qualquer dose em comparação com a ausência do hidro-retentor. O IQD pode ser considerado um bom parâmetro para indicar o padrão de qualidade das mudas crescidas sob diferentes doses de hidrogel, pois apresenta elevada correlação de Pearson (Tabela 2) com os outros parâmetros indicativos de qualidade (altura, diâmetro do coleto, MSPA, MSR e MST). Serve para confirmar que, sob algumas doses do hidrogel, principalmente próximas a 4,5 g.L $\mathrm{L}^{-1}$, as mudas apresentam melhor qualidade para o plantio, pois o valor de seus parâmetros constituintes está dentro dos limites considerados adequados para o plantio, considerando-se a altura de $25 \mathrm{~cm}$ e o diâmetro do coleto próximo a $2 \mathrm{~mm}$, de acordo com Sturion et al. (2000).

Cabe destacar também o aspecto gelatinoso sobre os tubetes quando se faz uso de dosagens muito altas. A dose de 3 g. $\mathrm{L}^{-1}$ ou inferior do hidro-retentor apresenta alguns aglomerados gelatinosos sobre o tubete, mas sem qualquer extrapolação do recipiente. A dose de 4,5 g.. $\mathrm{L}^{-1}$ apresentou mais aglomerados com esse aspecto, porém também não havendo extravasamento dos tubetes, o que ocorreu na dose superior $\left(6 \mathrm{~g} . \mathrm{L}^{-1}\right)$. O vazamento de hidrogel hidratado juntamente com substrato dos tubetes pode expulsar a muda do recipiente, ou provocar o excesso de umidade sobre o tubete, o que pode ocasionar o aparecimento de musgos ou doenças nas mudas. 


\section{Análise nutricional da parte aérea das mudas}

As doses do hidrogel influenciaram a concentração de macro e micronutrientes de mudas de E. dunnii $(p<0,05)$. $\mathrm{O}$ teor de $\mathrm{N}$ aumentou à medida que foram adicionadas maiores doses de hidrogel no substrato, com ajuste linear crescente da equação (Figura 3A). O teor de $\mathrm{N}$ não foi superior com o uso da dose $1,5 \mathrm{~g} . \mathrm{L}^{-1}$ de hidrogel em comparação à testemunha, mostrando que dosagens muito baixas do polímero não proporcionam grande acúmulo de $\mathrm{N}$ nos tecidos vegetais.

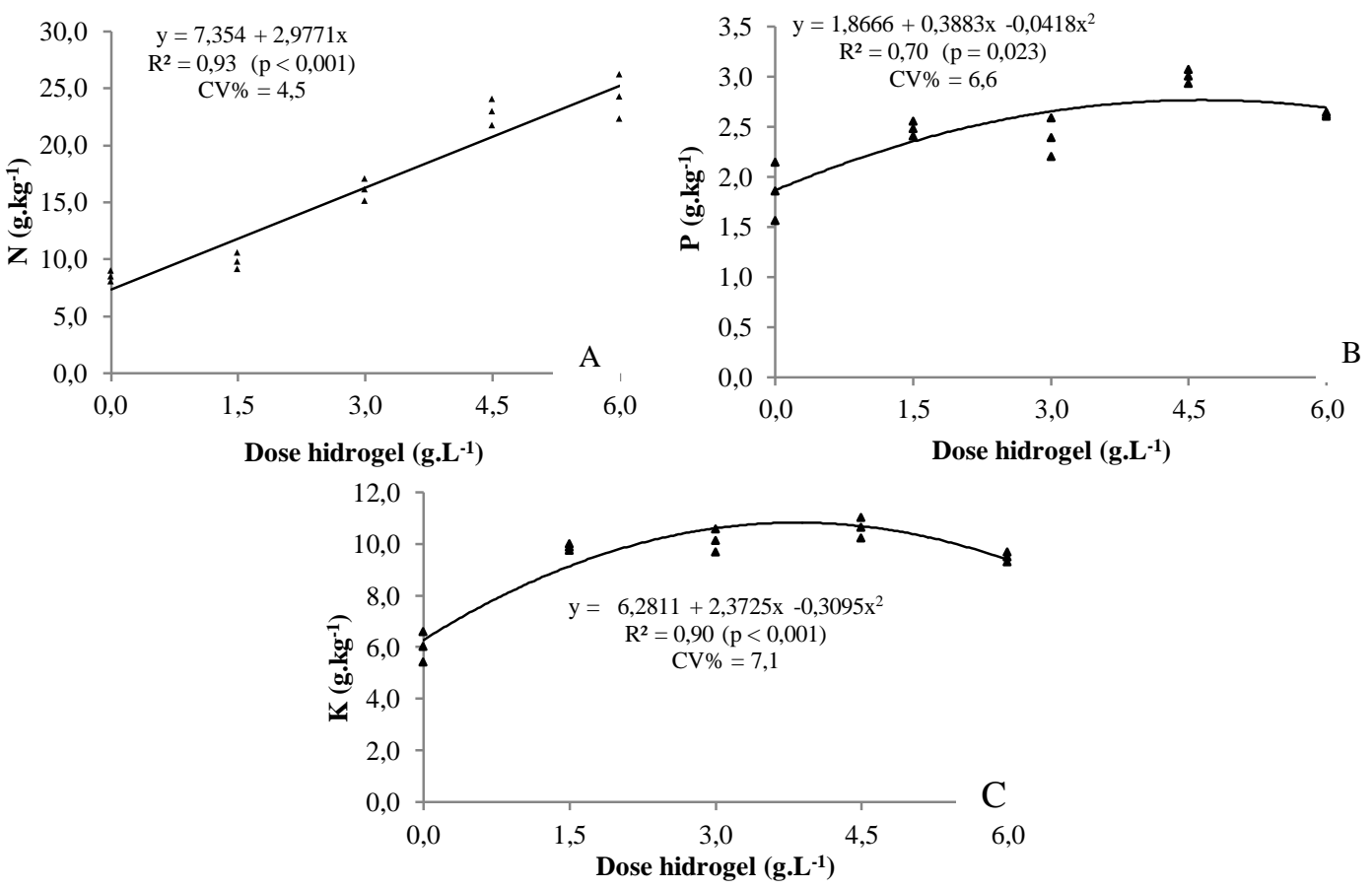

Figura 3. Efeitos da adição de diferentes doses de hidrogel no teor de macronutrientes de N (A), P (B) e $\mathrm{K}(\mathrm{C})$ da parte aérea (caule + folhas) de mudas de Eucalyptus dunnii aos 90 dias em viveiro.

Figure 3. Effects of adding different dosages of hydrogel in the macronutrients of $N(A), P(B)$ and $K(C)$ shoot (stem + leaves) of seedlings of Eucalyptus dunnii 90 days in the nursery.

Apesar da maior dose de hidrogel utilizada $\left(6,0 \mathrm{~g} . \mathrm{L}^{-1}\right)$ ter apresentado a maior concentração de nitrogênio, não houve efeito positivo no crescimento das mudas de $E$. dunnii na etapa de viveiro. De maneira geral, para a maioria das variáveis morfológicas analisadas, doses superiores a $4,5 \mathrm{~g} . \mathrm{L}^{-1}$ causaram diminuição no crescimento das plantas, possivelmente em razão do excesso de água no substrato.

Conforme os teores de $\mathrm{N}$ considerados ideais $\left(13\right.$ a $\left.15 \mathrm{~g}^{-\mathrm{kg}^{-1}}\right) \mathrm{em}$ mudas de E. grandis, estabelecidos por Silveira et al. (1995a, b), pode-se considerar que o teor de $\mathrm{N}$ está em uma faixa mais adequada para o tratamento com o uso de $3 \mathrm{~g} . \mathrm{L}^{-1}$ do polímero. Na ausência do hidrogel e na presença de $1,5 \mathrm{~g} . \mathrm{L}^{-1}$, o teor foi abaixo do considerado ideal. Já nas doses acima de $3 \mathrm{~g} . \mathrm{L}^{-1}$ há um excesso no teor, o que também pode comprometer o desenvolvimento e a qualidade das mudas, fato que foi observado na diminuição da altura das mudas com o uso de 6 g.. $\mathrm{L}^{-1}$ de hidrogel. Cabe ressaltar que os teores considerados ideais para os autores citados são para $E$. grandis, não havendo referências para $E$. dunnii.

Esse efeito prejudicial do $\mathrm{N}$ em quantidade além do ideal é exposto por Taiz e Zeiger (2009), os quais descrevem que, embora o nitrogênio seja um dos elementos minerais que as plantas exigem em maiores quantidades, servindo como constituinte em diversos componentes das células, incluindo aminoácidos, proteínas e ácidos nucleicos, o seu excesso pode prejudicar o crescimento das plantas.

Para os elementos $\mathrm{P}$ e $\mathrm{K}$, os maiores teores nutricionais nos tecidos vegetais foram obtidos próximos à dose 4,5 g. $\mathrm{L}^{-1}$ de hidrogel (Figura $3 \mathrm{~B}$ e C), tendendo a diminuir o teor de ambos os macronutrientes com aumento da dose para $6,0 \mathrm{~g} \cdot \mathrm{L}^{-1}$.

A relação adequada entre os nutrientes nitrogênio e potássio na fase de crescimento deve estar na faixa de 1,4 até 2,0, conforme recomendam Silveira et al. (1995a, b). Essa faixa ideal da relação foi obtida com uso de $3 \mathrm{~g} . \mathrm{L}^{-1}$ do polímero hidro-retentor, tendendo a aumentar a relação com o uso de 
maiores doses. O fósforo apresenta grande importância no desenvolvimento dos vegetais, sendo o elemento, depois do nitrogênio, que mais restringe o crescimento das plantas em caso de deficiência. Comparativamente às referências do E. grandis (SILVEIRA et al., 1995a, b), somente o tratamento testemunha (sem adição de hidrogel) está na faixa considerada ideal $\left(1,5\right.$ a 2,0 g. $\left.\mathrm{kg}^{-1}\right)$. Os demais tratamentos apresentam teores acima dessa faixa. Essa diferença nos teores pode ser devida às diferentes necessidades das espécies por esse nutriente. Em comparação com outras espécies florestais, os maiores teores obtidos então dentro do considerado ideal. Sorreano et al. (2012), em Astronium graveolens Jacq., obtiveram teores de P de 4,5 g. $\mathrm{kg}^{-1} ; 2,8$ g.kg-1 em Tapirira guianensis Aubl.; $2,8 \mathrm{~g} . \mathrm{kg}^{-1} \mathrm{em}$ Cecropia pachystachya Trécul.; 2,4 g. $\mathrm{kg}^{-1} \mathrm{em}$ Acacia polyphylla DC.; 3,2 g. $\mathrm{kg}^{-1} \mathrm{em}$ Enterolobium contorstisiliquum (Vell.) Morong.; e 3,1 g.kg ${ }^{-1}$ em Ceiba speciosa (St.-Hill.).

Em relação ao potássio, observa-se que, comparativamente às referências do E. grandis, todos os tratamentos apresentaram teores nutricionais bastante inferiores aos ideais $(15$ a 20 g.kg-1 $)$. O resultado obtido com E. dunnii pode indicar diferentes exigências das espécies pelo elemento, já que se observa uma tendência de queda do teor de potássio com o uso superior a $4,5 \mathrm{~g} \cdot \mathrm{L}^{-1}$ do hidrogel. A lixiviação do nutriente no substrato, possivelmente, não foi a causa da diminuição do teor nutricional com aumento da dose do hidrogel, podendo-se apontar outras causas, como a elevação da umidade no substrato, a qual causa menor absorção do nutriente pela planta. Sintomas de deficiência também não foram observados, o que pode evidenciar a menor necessidade por esse nutriente na espécie durante esse estágio de desenvolvimento da planta.

A adição de hidrogel ao substrato até certo limite colaborou com o aumento do teor de $\mathrm{K}$, possivelmente em razão da diminuição da lixiviação do nutriente. Gomes (2001) relatou que o K é um elemento de grande lixiviação, não sendo esperadas respostas residuais por longos períodos. O autor comenta ainda que a fertilização potássica na adubação de base é, praticamente, desnecessária para o crescimento de mudas de espécies florestais, em razão da alta lixiviação. Dessa forma, o hidrogel pode reter certa quantidade do nutriente e disponibilizá-lo à planta por maior tempo.

Fernandes (2010), em estudo utilizando o polímero à base de poliacrilamida em indivíduos de $E$. urophylla S. T. Blake cultivados em vaso e avaliados aos 126 dias, demonstrou aumento do teor de potássio na parte aérea com o aumento da dose do hidrogel. $\mathrm{O}$ autor encontrou quase o dobro de $\mathrm{K}$ $\left(2,08 \mathrm{~g} \cdot \mathrm{kg}^{-1}\right)$ com o uso de $8 \mathrm{~g}$ de hidrogel por planta em comparação à dose zero $\left(1,12 \mathrm{~g} \cdot \mathrm{kg}^{-1}\right)$. Apesar da tendência de aumento do teor de $\mathrm{K}$ com o aumento da dose do hidrogel, as quantidades obtidas são muito inferiores às encontradas neste estudo. Essa diferença de valores pode ser devida aos teores e conteúdos de nutrientes variarem com o desenvolvimento da cultura.

Com relação ao teor de cálcio, verificou-se que na ausência do hidrogel o teor do nutriente foi menor ao obtido nos tratamentos que tiveram adição do polímero (Figura 4A). Divergindo dos demais macronutrientes, que expressaram o máximo de teores quando foi realizado o uso de doses mais altas do hidrogel, o $\mathrm{Ca}$ apresentou os maiores valores na dose $1,5 \mathrm{~g} . \mathrm{L}^{-1}$, diminuindo com o aumento da dose do hidrogel. Apesar de o teor encontrado em $E$. dunnii ser muito inferior ao encontrado em $E$. grandis Hill (ex Maiden) (8-12 g.kg-1), não foram observados sintomas de deficiência de Ca nas mudas. Possivelmente, o $E$. dunnii possui menor exigência também desse nutriente, a exemplo do observado com $\mathrm{K}$.

$\mathrm{O}$ teor de Magnésio comportou-se de maneira quadrática (Figura 4B), aumentando até a concentração 4,5 g. $\mathrm{L}^{-1}$ do hidrogel e após tendendo a diminuir com o aumento da dose do polímero. $\mathrm{O}$ teor de $\mathrm{Mg}$ foi bem inferior no tratamento testemunha sem adição do hidrogel, mostrando que, a exemplo dos demais macronutrientes, o hidrogel proporcionou maior absorção desses nutrientes. Comportamento similar foi obtido para o enxofre (Figura 4C). Neste, a maior diferença ocorreu na dose $1,5 \mathrm{~g} . \mathrm{L}^{-1}$ de hidrogel, que praticamente não variou da ausência do polímero.

Em comparação aos valores considerados ideais por Silveira et al. (1995a, b) para E. grandis, a adição de hidrogel proporcionou o enquadramento dos teores na faixa adequada $(3,0$ a 3,5 e 1,3 a $1,5 \mathrm{~g} . \mathrm{kg}^{-1}$, respectivamente, para Mg e S). Para o magnésio, a adição de $1,5 \mathrm{~g} . \mathrm{L}^{-1}$ de hidrogel foi suficiente para a obtenção dos níveis ideais, sendo que o aumento da dose provocou uma elevação dos níveis. Para o $\mathrm{S}$, o uso do hidrogel na faixa de 3,0 a 4,5 g.L $\mathrm{L}^{-1}$ ajustou os teores aos encontrados pelos autores.

$\mathrm{O}$ aumento da retenção de água no substrato de cultivo (Tabela 1) ocasionou consequentemente a diminuição da lixiviação de nutrientes no substrato, principalmente dos macronutrientes (TAYLOR; HALFACRE, 1986). Com o aumento da disponibilidade dos macronutrientes no substrato, há maior absorção por parte da planta (AZEVEDO et al., 2002), o que explica o maior teor na parte aérea das mudas com o uso do hidrogel. Com a diminuição dos processos de lixiviação do substrato, houve a elevação do pH

FLORESTA, Curitiba, PR, v. 45, n. 2, p. 315 - 328, abr. / jun. 2015.

Navroski. M. C. et al.

ISSN eletrônico 1982-4688 / ISSN impresso 0015-3826

323

DOI: $10.5380 /$ rf.v45i2.34411 
(Tabela 1), o que também pode ter ocasionado o aumento da disponibilidade dos macronutrientes, já que entre $\mathrm{pH}$ 6,0 e 6,5 existe maior disponibilidade de nutrientes (NOVAIS et al., 2007).
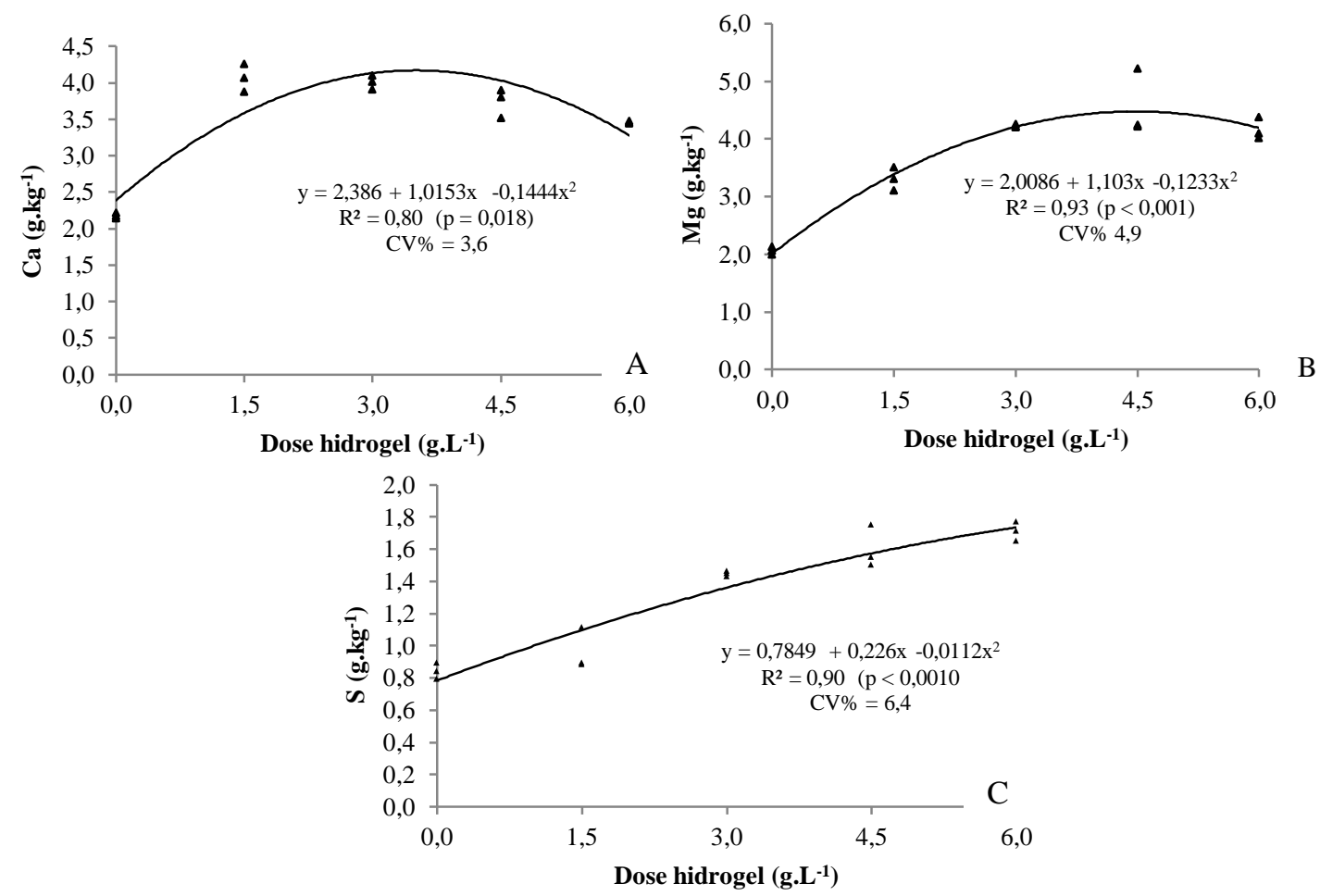

Figura 4. Efeitos da adição de diferentes doses de hidrogel no teor de macronutrientes de $\mathrm{Ca}$ (A), $\mathrm{Mg}$ (B) e $\mathrm{S}(\mathrm{C})$ da parte aérea (caule + folhas) de mudas de Eucalyptus dunnii aos 90 dias em viveiro.

Figure 4. Effects of adding different dosages of hydrogel in the macronutrients $\mathrm{Ca}(\mathrm{A}), \mathrm{Mg}(\mathrm{B})$ and $\mathrm{S}(\mathrm{C})$ shoot (stem + leaves) of seedlings of Eucalyptus dunnii 90 days in the nursery.

Pela análise dos teores de micronutrientes, observou-se comportamento quadrático para todos os elementos (Figura 5). Todos os micronutrientes obtiveram maiores teores ( $\mathrm{mg}^{\mathrm{kg}} \mathrm{kg}^{-1}$ ) na ausência de hidrogel, diminuindo com a adição do polímero, à exceção do $\mathrm{Cu}$, que apresentou tendência de queda com o aumento da dose de hidrogel. Os demais micronutrientes apresentaram tendência de estabilização dos teores.

O teor de boro na parte aérea de mudas de E. dunnii decresceu com o aumento da dose de hidrogel (Figura 5A). Comportamento similar do boro foi obtido por Fernandes (2010), avaliando o teor nutricional de E. urophylla em função da dose de hidrogel e frequências de irrigação. Apesar de a análise ser realizada utilizando somente o caule da muda, o teor de boro também diminuiu com o aumento da dose de polímero à base de poliacrilamida.

Neste estudo, o pH aumentou conforme a adição do hidrogel ao substrato $(4,8$ até 6,3$)$, o qual é um dos principais fatores que afetam a disponibilidade de boro. $\mathrm{O}$ aumento do $\mathrm{pH}$ diminui o teor de boro na solução, devido à maior adsorção desse nutriente na superfície dos coloides à medida que cresce a alcalinidade do meio (FERREIRA, 1998).

Em relação ao cobre, houve diminuição do teor com o aumento da dose do polímero hidroretentor à base de poliacrilamida (Figura 5B), fato que também foi observado no trabalho de Fernandes (2010). O teor encontrado pelo autor variou de $275,87 \mathrm{mg} \cdot \mathrm{kg}^{-1}$ na ausência de hidrogel para $157,24 \mathrm{mg} \cdot \mathrm{kg}^{-1}$ com o uso de $8 \mathrm{~g}$ por planta em mudas de E. urophylla aos 126 dias de idade. Entretanto, o teor foi avaliado em caules, justificando a diferença de teor encontrada neste estudo. A mobilidade do $\mathrm{Cu}$ dentro das plantas é limitada e particularmente dependente do estado nutricional em termos de $\mathrm{Cu}$ e de N (KIRKBY; RÖMHELD, 2004).

O cobre apresenta-se fortemente ligado aos coloides organominerais, e quanto maior o teor de matéria orgânica, menor sua disponibilidade nas plantas, estando fortemente relacionado ao valor do $\mathrm{pH}$. 
Essa diminuição dos teores de cobre nos tecidos das mudas pode ser explicada pelo aumento do $\mathrm{pH}$ conforme as doses do hidrogel, sendo que condições de $\mathrm{pH}$ acima de 6 favorecem a sua retenção (PRADO, 2008). Esse elemento é classificado como um elemento pouco móvel pelo floema da planta, podendo existir inibições competitivas entre o cobre e o zinco (MALAVOLTA et al., 1997). Seu teor total em plantas pode variar de 1 a $5 \mathrm{mg} \cdot \mathrm{kg}^{-1}$, podendo atingir $100 \mathrm{mg} \cdot \mathrm{kg}^{-1} \mathrm{em}$ folhas mais velhas, sendo que a sua toxidez não é comum, porém pode ocorrer principalmente nos estádios iniciais de crescimento da planta (PRADO, 2008).
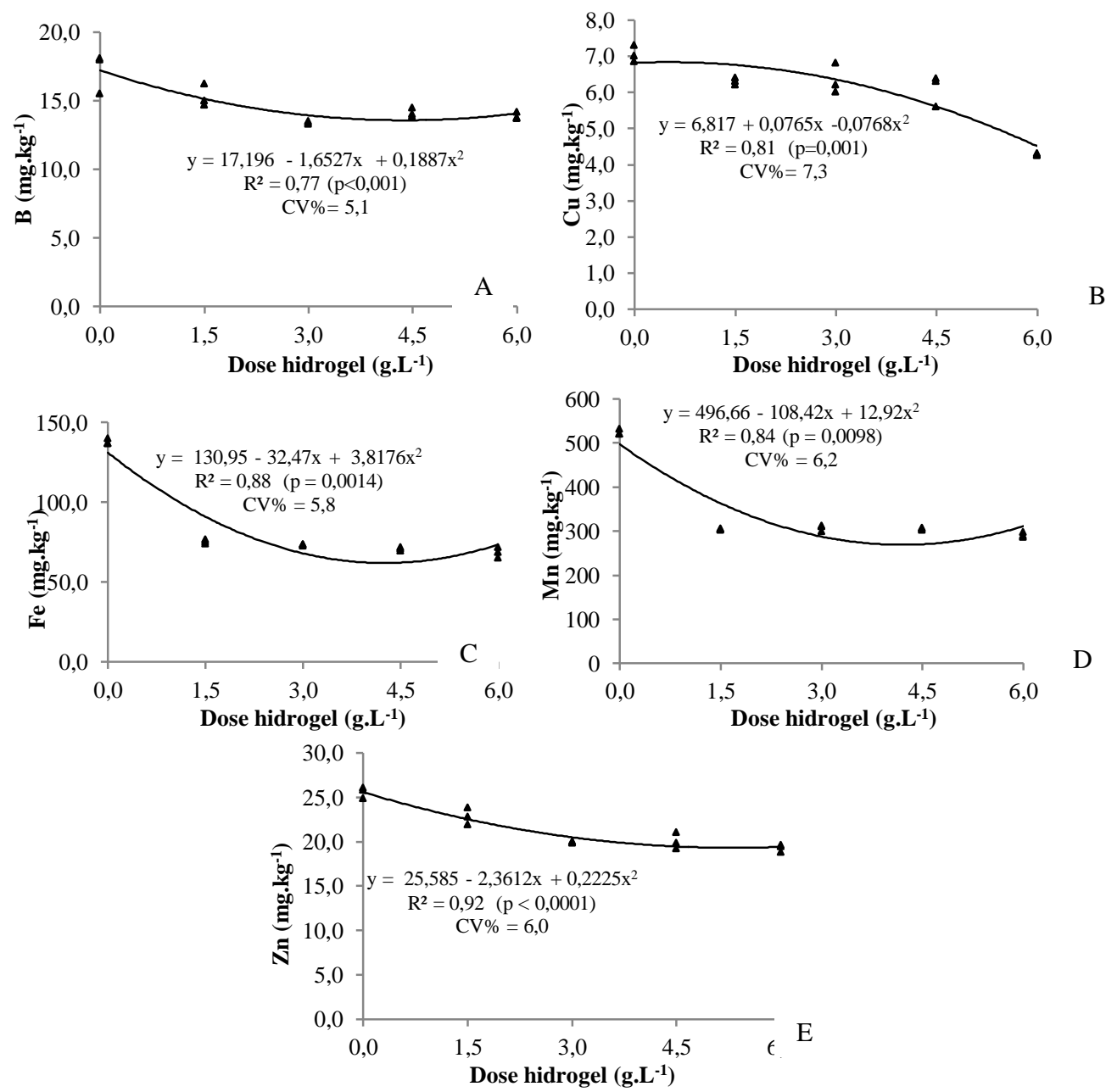

Figura 5. Efeitos da adição de diferentes doses de hidrogel no teor de micronutrientes de B (A), Cu (B), $\mathrm{Fe}(\mathrm{C}), \mathrm{Mn}(\mathrm{D})$ e $\mathrm{Zn}$ (E) da parte aérea (caule + folhas) de mudas de Eucalyptus dunnii aos 90 dias em viveiro.

Figure 5. Effects of adding different dosages of the hydrogel micronutrient content B (A), Cu (B), $\mathrm{Fe}(\mathrm{C}), \mathrm{Mn}(\mathrm{D})$ and $\mathrm{Zn}(\mathrm{E})$ of the shoot (stem + leaves) the seedlings Eucalyptus dunnii 90 days in the nursery.

O suprimento adequado do ferro depende mais das condições de $\mathrm{pH}$ (maior disponibilidade em $\mathrm{pH}$ ácido, < 6,0), da umidade e da aeração do que propriamente da quantidade presente no solo, que, normalmente, é abundante. Além disso, concentrações elevadas de outros íons na solução do meio (P, Mn e Zn) podem inibir a absorção de Fe por competição iônica (PRADO, 2008). Esse efeito inibitório de outros elementos, principalmente do P, pode ter sido fator limitante para o teor de Fe, verificando-se que o fósforo aumentou com dosagens mais elevadas do hidrogel e o ferro diminuiu (Figura 5C). 
No estudo de Fernandes (2010), o teor de ferro nas folhas de E. urophylla aos 126 dias de idade não variou com a quantidade de hidrogel, sendo observada média de $129,43 \mathrm{mg} \cdot \mathrm{kg}^{-1}$ do nutriente, valor próximo ao encontrado neste estudo na ausência do hidrogel $\left(137,82 \mathrm{mg} \cdot \mathrm{kg}^{-1}\right)$.

$\mathrm{O}$ manganês é um dos micronutrientes mais abundantes nos tecidos vegetais. Fatores como $\mathrm{pH}$, potencial de oxirredução, matéria orgânica e equilíbrio com outros cátions influenciam na sua disponibilidade (PRADO, 2008). Esse elemento compete e reduz a absorção de outros, particularmente a de $\mathrm{Ca}, \mathrm{Mg}$ e Fe e, em menor nível, a de K (MARENCO; LOPES, 2005). Mikkelsen (1995), trabalhando com cultura de soja em casa de vegetação, analisou o efeito do hidrogel juntamente com $\mathrm{MnO}$ (óxido de manganês), $\mathrm{MnSO}_{4} \cdot 4 \mathrm{H}_{2} \mathrm{O}$ (sulfato de manganês) e $\mathrm{MnCl}$ (cloreto de manganês), registrando um aumento no acúmulo de Mn na folha para todas as fontes de nutrientes analisadas na presença do polímero, ao contrário deste estudo, que, com o hidrogel, registrou diminuição do teor de Mn (Figura 5D). O zinco apresentou comportamento similar ao dos demais micronutrientes (Figura 5E), diminuindo o teor com o aumento da dosagem do hidrogel.

O requerimento nutricional médio (obtido da média de todas as doses do hidrogel) de mudas de E. dunnii, aos 90 dias em viveiro, obedeceu, em ordem decrescente, a seguinte classificação: $\mathrm{N}>\mathrm{K}>\mathrm{Mg}>\mathrm{Ca}>\mathrm{P}>\mathrm{S}$ (macronutrientes) e $\mathrm{Mn}>\mathrm{Fe}>\mathrm{Zn}>\mathrm{B}>\mathrm{Cu}$ (micronutrientes). Comparando com as taxas consideradas adequadas para as folhas de mudas de E. grandis, com idade entre 80-100 dias, conforme proposto por Silveira et al. (1995a, b), observa-se que os teores de N, P e Mg estão acima do descrito pelos autores. Os teores de S, Fe e Mn estão dentro da faixa considerada adequada, e os demais elementos (K, Ca, B, Cu e Zn) estão abaixo do recomendado.

Landis (1989) salienta que cada viveiro deve possuir seu próprio padrão de análise nutricional, determinando as causas de variações existentes entre as espécies, fases de crescimento das plantas e práticas de cultivo. $\mathrm{O}$ mesmo autor complementa que a fertilização excessiva (especialmente de $\mathrm{N}$ ) ocasiona o consumo desnecessário dos nutrientes, a inibição do desenvolvimento de micorrizas e a contaminação das águas residuais, além dos efeitos adversos, devido à toxicidade.

Vichiato et al. (2004) afirmaram que a incorporação do hidro-retentor ao substrato de cultivo de porta-enxerto Tangerina Cleópatra não promoveu alteração expressiva no estado nutricional dos portaenxertos, aos 150 dias pós-semeadura. Entretanto, a incorporação do hidrogel elevou o pH do substrato. Nesse caso, segundo Bernardi et al. (2012), o aumento do $\mathrm{pH}$ poderia reduzir a disponibilidade de alguns micronutrientes ( $\mathrm{Fe}, \mathrm{Mn}, \mathrm{Zn}$ ) e consequentemente o teor nutricional na parte aérea das plantas, fato que foi observado neste estudo.

De uma forma geral, os macronutrientes apresentaram maior teor na planta quando de seu cultivo na presença do hidrogel. $\mathrm{O}$ teor de $\mathrm{N}$ e $\mathrm{S}$ aumentaram de forma progressiva com o aumento da quantidade do hidrogel e P, K, Ca e Mg obtiveram maior teor na faixa entre 1,5 a 4,5 g. $\mathrm{L}^{-1}$ do polímero. Em relação aos micronutrientes, altas doses do hidrogel ocasionaram redução no teor nutricional de todos os elementos.

\section{CONCLUSÕES}

- A dose 4,5 g.. $\mathrm{L}^{-1}$ de hidrogel eleva o crescimento e a qualidade das mudas de E. dunnii.

- O teor dos macronutrientes na parte aérea das mudas aumenta com a adição do hidrogel, porém diminui o teor dos micronutrientes.

\section{REFERÊNCIAS}

ARAÚJO, D. D. Crescimento de mudas de Jatoba (Hymenaea courbaril) sob quatro níveis de sombreamento. 144 f. Tese (Ministério da Educação. Ministério da Ciência e Tecnologia) Universidade Federal Rural da Amazónia. Belém, PA, 2009.

AZEVEDO, T. L. F.; BERTONHA, A.; GONÇALVES, A. C. A.; TAS, P. S. L., FRIZZONE, J. A. Níveis de polímero superabsorvente, frequência de irrigação e crescimento de mudas de café. Acta Scientiarum, Maringá, v. 24, n. 5. p. 1239 - 1243, 2002.

BERNARDI, M. R.; SPEROTTO JUNIOR, M.; DANIEL, O.; VITORINO, A. C. T. Crescimento de mudas de Corymbia citriodora em função do uso de hidrogel e adubação. Cerne, Lavras, v. 18, n. 1, p. 67 - 74, 2012.

CÂMARA, G. R.; REIS, D. F.; ARAÚJO, G. L.; CAZOTTI, M. M.; DONATELLI JUNIOR, E. J. Avaliação do desenvolvimento do cafeeiro Conilon robusta tropical mediante uso de polímeros hidroretentores e diferentes turnos de rega. Enciclopédia Biosfera, Goiânia, v. 7, n. 13; p. 135 - 146, 2011. 
COTTHEM, W. V. O papel de Terracottem como um absorvente universal. Bélgica: Ghent, 1998.

DICKSON, A.; LEAF, A. L.; HOSNER, J. F. Quality appraisal of white spruce and white pine seedling stock in nurseries. Forest Chronicle, Mattawa, v. 36, p. 10 - 13, 1960.

DUSI, D. M. Efeito da adição do polímero hidro-retentor na eficiência da adubação nitrogenada no crescimento de Brachiaria decumbens cv. Basilisk, em dois diferentes substratos. $84 \mathrm{f}$. Dissertação (Mestrado em Engenharia Florestal) - Universidade Federal do Paraná, Curitiba, 2005.

ELOY, E.; CARON, B. O.; SCHMIDT, D.; BEHLING, A.; SCHWERS, L.; ELLI, E. F. Avaliação da qualidade de mudas de Eucalyptus grandis utilizando parâmetros morfológicos. Revista Floresta, Curitiba, v. 43, n. 3, p. 373 - 384, 2013.

ENGEL, V. L.; POGGIANI, F. Influência do sombreamento sobre o crescimento de mudas de algumas essências nativas e suas implicações ecológicas e silviculturais. Instituto de Pesquisas e Estudos Florestais, Piracicaba, n. 43 - 44, p. 1 - 10, 1990.

FERMINO, M. H. Métodos de análise para caracterização física de substratos. 89 p. Tese (Doutorado em Fitotecnia) - Universidade Federal do Rio Grande do Sul, Porto Alegre, 2003.

FERNANDES, E. R. P. Hidrogel e turno de rega no crescimento inicial de eucalipto. 35 p. Dissertação (Mestrado em Produção vegetal) - Universidade Federal dos Vales do Jequitinhonha e Mucuri, 2010.

FERREIRA, D. F. Sisvar: a computer statistic analysis system. Ciência e Agrotecnologia, Lavras, v. 35, n. 6, p. 1039 - 1042, 2011.

FERREIRA, G. B. Interferências da matéria orgânica e ferro na dose de boro com Azometina-H e comparação de extratores para boro disponível no solo. 97 p. Dissertação (Mestrado em Solos) Universidade Federal de Viçosa, Viçosa, 1998.

GOMES, J. M. Parâmetros morfológicos na avaliação da qualidade de mudas de Eucalyptus grandis, produzidas em diferentes tamanhos de tubetes e de dosagens de N-P-K. $112 \mathrm{f}$. Tese (Doutorado em Ciência Florestal) - Universidade Federal de Viçosa, Viçosa, 2001.

GOMES, J. M.; COUTO, L.; LEITE, H. G.; XAVIER, A.; GARCIA, S. L. R. Crescimento de mudas de Eucalyptus grandis em diferentes tamanhos de tubetes e fertilização N-P-K. Revista Árvore, Viçosa, v. 27, n. 2, p. 113 - 127, 2003.

GOMES, J. M.; PAIVA, H. N.; COUTO, L. Produção de mudas de eucalipto. In: Informe Agropecuário, EPAMIG, Belo Horizonte, v. 18, n. 185, p. 15 - 22, 1996.

HAFLE, O. M.; CRUZ, M. C. M.; RAMOS, J. D.; RAMOS, P. S.; SANTOS, V. A. Produção de mudas de maracujazeiro-doce através da estaquia utilizando polímero hidro-retentor. Revista Brasileira de Ciências Agrárias, Recife, v. 3, n. 3, p. 232 - 236, 2008.

INSTITUTO NACIONAL DE METEOROLOGIA (INMET). Banco de Dados Meteorológicos para Ensino e Pesquisa. Disponível em: <http://www.inmet.gov.br/projetos/rede/pesquisa/form_mapas_ mensal.php>. Acesso em 12 de agosto de 2013.

JACOBS, D. F.; LANDIS, T. D. Fertilization. In: DUMROESE, R. K.; LUNA, T.; LANDIS, T. D. (Eds.). Nursery manual for native plants: a guide for tribal nurseries. Agriculture Handbook 730. Washington, D.C.: U.S. Department of Agriculture, Forest Service, v. 1, 2009, p. 201 - 215.

KÄMPF, A. N. Produção comercial de plantas ornamentais. 2. ed. Guaíba: Agrolivros, 2005. 256 p.

KIRKBY, E. A.; RÖMHELD, V. Micronutrients in Plant Physiology: Functions, Uptake and Mobility. Proceedings n. 543, International Fertiliser Society, York, UK, 1 - 51, 2004.

LANDIS, T. D. Mineral nutrients and fertilization. In: LANDIS, T. D.; TINUS, R. W.; McDONALD, S. E.; BARNETT, J. P. The container tree nursery manual. Agriculture Handbook 674. Washington, D.C.: U.S. Department of Agriculture, Forest Service, v. 4, 1989. p. 1 - 67.

LIMA, L. M. L.; TEODORO, R. E. G.; FERNANDES, D. L.; CARVALHO, H. P.; MENDONÇA, F. C.; CARVALHO, J. O. M. Produção de mudas de café sob diferentes lâminas de irrigação e doses de um polímero hidroabsorvente. Bioscience in Journal, v. 19, n. 3, p. 27 - 30, 2003.

MALAVOLTA, E.; VITTI, G. C.; OLIVEIRA, S. A. de. Avaliação do estado nutricional das plantas: princípios e aplicações. 2. ed. Piracicaba: POTAFOS, 1997. 319 p.

FLORESTA, Curitiba, PR, v. 45, n. 2, p. 315 - 328, abr. / jun. 2015.

Navroski. M. C. et al.

ISSN eletrônico 1982-4688 / ISSN impresso 0015-3826

327

DOI: $10.5380 /$ rf.v45i2.34411 
MARENCO, R. A.; LOPES, N. F. Fisiologia vegetal: fotossíntese, respiração, relações hídricas e nutrição mineral. Viçosa, MG: Editora UFV, 2005, 451 p.

MARQUES, P. A. A.; BASTOS, R. O. Uso de diferentes doses de hidrogel para produção de mudas de pimentão. Pesquisa Aplicada \& Agrotecnologia, Guarapuava, v. 3, n. 2, p. 53 - 57, 2010.

MARQUES, P. A. A.; CRIPA, M. A. M.; MARTINEZ, E. H. Hidrogel como substituto da irrigação complementar em viveiro telado de mudas de cafeeiro. Ciência Rural, Santa Maria, v. 43, n. 1, p. 1 - 7, 2013.

MELO, B.; ZAGO, R.; SANTOS, C. M.; MENDONÇA, F. C.; SANTOS, V. L. M.; TEODORO, R. E. F. Uso do polímero hidroabsorvente Terracottem e da frequência de irrigação na produção de mudas de cafeeiro em tubetes. Revista Ceres, Viçosa, n. 52, p. 13 - 22, 2005.

MIKKELSEN, R. L.; BEHEL, A. D.; WILLIAMS, H. M. Using idrophilic polymers to improve uptake of manganese fertilizers by soybeans. Fertilizer Research, v. 41, p. 87 - 92, 1995.

MINISTÉRIO DA AGRICULTURA, PECUÁRIA E ABASTECIMENTO (MAPA). Instrução Normativa SDA no 17. Diário Oficial da União - Seção 1, no 99, 24 de maio de 2007. Métodos Analíticos Oficiais para Análise de Substratos para Plantas e Condicionadores de Solo. Brasília, 2007.

MIYAZAWA, L. C. Manual de análises químicas. Brasília: EMBRAPA, 1999. 370 p.

MORAES, O.; BOTREL, T. A.; DIAS, C. T. S. Efeito do uso de polímero hidro-retentor no solo sobre intervalo de irrigação na cultura da alface (Lactuca sativa L.). Engenharia Rural, Piracicaba, v. 12, p. 73 - 80, 2001.

MOREIRA, R. A.; RAMOS, J. D.; CRUZ. M. C. M; VILLAR, L.; HAFLE, O. M. Efeito de doses de polímero hidroabsorvente no enraizamento de estacas de amoreira. Revista Agrarian, Dourados, v. 3, n. 8, p. 133 - 139, 2010.

PRADO, R. M. Nutrição de plantas. São Paulo: Ed. UNESP, 2008. 407 p.

SAAD, J. C. C.; LOPES, J. L. W.; SANTOS, T. A. Manejo hídrico em viveiro e uso de hidrogel na sobrevivência pós-plantio de Eucalyptus urograndis em dois solos diferentes. Engenharia Agrícola, Jaboticabal, v. 29, n. 3, p. 404 - 411, 2009.

SILVEIRA, R. L. V. A.; LUCA, E. F.; SHIBATA, F. Absorção de macronutrientes pelas mudas de Eucalyptus grandis em condição de viveiro. In: CONGRESSO BRASILEIRO DE CIÊNCIA DO SOLO, 25, Viçosa, 1995. Anais...Viçosa: SBCS/UFV, 1995a, p. 839 - 841.

SILVEIRA, R. L. V. de A.; LUCA, E. F. de; SHIBATA, F.; CHALITA, L. V. de A. Absorção de micronutrientes pelas mudas de Eucalyptus grandis em condição de viveiro. In: CONGRESSO BRASILEIRO DE CIÊNCIA DO SOLO, 25, Viçosa, 1995. Anais... Viçosa: SBCS/UFV, 1995b. p. 842 - 844.

SORREANO, M. C. M.; RODRIGUES, R. R.; BOARETTO, A. E. Guia de nutrição para espécies nativas. Oficina de Textos, 2012. $256 \mathrm{p}$.

SOUSA, G. T. O.; AZEVEDO, G. B.; SOUSA, J. R. L.; MEWS, C. L.; SOUZA, A. M. Incorporação de polímero hidro-retentor no substrato de produção de mudas de Anadenanthera peregrina (L.) Speg. Enciclopédia Biosfera, Goiânia, v. 9, n. 16; p. 1270 - 1278, 2013.

STURION, J. A.; ANTUNES, B. M. Produção de mudas de espécies florestais. In: GALVÃO, A. P. M. Reflorestamento de propriedades rurais para fins de produtivos e ambientais. Colombo: 2000. p. 125 - 150.

TAIZ, L.; ZEIGER, E. Fisiologia vegetal. 4. ed. Porto Alegre: Artmed, 2009. 848 p.

TAYLOR, K. C.; HALFACRE, R. G. The effect of hydrophilic polymer on media water retention and nutrient availability to Ligustrum lucidum. Horticulture Science, v. 21, p. 1159 - 1161, 1986.

TEDESCO, M. J. Análise de solo, planta e outros materiais. 2. ed. Porto Alegre: Universidade Federal do Rio Grande do Sul, 1995. 174 p. il. (Boletim Técnico, 5).

VICHIATO, M.; VICHIATO, M. R. M.; SILVA, C. R. R. Crescimento e composição mineral do portaenxerto de tangerina Cleópatra cultivado em substrato acrescido de polímero hidro-retentor. Ciência e Agrotecnologia, Lavras, v. 28, n. 4, p. 748 - 756, 2004.

WENDLING, I.; GATTO, A.; PAIVA, H. N. Substratos, adubação e irrigação na produção de mudas. Viçosa: Aprenda Fácil Editora, 2002. 166 p. 